\title{
Evaluation of the fetal abdomen by magnetic resonance imaging. Part 2: abdominal wall defects and tumors
}

Avaliação do abdome fetal por ressonância magnética. Parte 2: malformações da parede abdominal e tumores

\section{Ana Paula Pinho Matos ${ }^{1}$, Luciana de Barros Duarte ${ }^{2}$, Pedro Teixeira Castro ${ }^{3}$, Pedro Daltro ${ }^{4}$, Heron Werner Júnior ${ }^{4}$, Edward Araujo Júnior ${ }^{5}$}

Matos APP, Duarte LB, Castro PT, Daltro P, Werner Jr H, Araujo Júnior E. Evaluation of the fetal abdomen by magnetic resonance imaging. Part 2: abdominal wall defects and tumors. Radiol Bras. 2018 Mai/Jun;51(3):187-192.

Abstract Although ultrasound is still the gold standard for the assessment of fetal malformations, magnetic resonance imaging (MRI) has gained great prominence in recent years. In situations in which ultrasound has low sensitivity, such as maternal obesity, abdominal scarring, and oligohydramnios, MRI has proven to be a safe and accurate method. Regarding fetal abdominal wall defects, MRI appears to be widely used in the prognostic assessment of gastroschisis with intestinal atresia or of complications of omphalocele, allowing better perinatal management and parental counseling. In addition, MRI allows the assessment of local invasion of fetal abdominal tumors, with significant prognostic value for the postnatal period. In this article, we review the main MRI findings in the evaluation of fetal abdominal wall defects and tumors.

Keywords: Fetus; Congenital abnormalities/diagnostic imaging; Abdomen/diagnostic imaging; Magnetic resonance imaging.

Resu mo Apesar de a ultrassonografia (US) ser o método padrão ouro na avaliação das malformações fetais, a ressonância magnética (RM) tem ganhado grande destaque nos últimos anos. Em algumas situações nas quais a US apresenta baixa sensibilidade, como obesidade materna, cicatrizes abdominais e oligo-hidrâmnio, a RM mostra-se um método seguro e com boa acurácia. Em relação às malformações da parede abdominal fetal, a RM mostra-se usual na avaliação prognóstica da atresia intestinal da gastrosquise ou complicações da onfalocele, permitindo melhor manejo perinatal e aconselhamento dos pais. Da mesma forma, a RM possibilita a avaliação de invasão local de tumores abdominais fetais, apresentando valor prognóstico pós-natal. Neste artigo, abordamos os principais achados na RM das malformações da parede abdominal fetal e tumores.

Unitermos: Feto; Anormalidades congênitas/diagnóstico por imagem; Abdome/diagnóstico por imagem; Ressonância magnética.

\section{INTRODUCTION}

The importance of imaging methods in the diagnosis of congenital malformations ${ }^{(1-3)}$, and especially in fetal medicine $^{(4-7)}$, has been the objective of a series of recent studies conducted in Brazil. Ultrasound continues to be the preferred method for evaluating fetal malformations because of its wide acceptance, low cost, and low risk for the mother and fetus. However, in certain conditions, such as maternal obesity, excessive fetal movement, abdominal

Study conducted in the Radiology Department of the Clínica de Diagnóstico Por Imagem (CDPI), Rio de Janeiro, RJ, Brazil.

1. MD, Physician in the Radiology Department of the Clínica de Diagnóstico Por Imagem (CDPI), Rio de Janeiro, RJ, Brazil.

2. PhD, Adjunct Professor in the Department of Maternal-Infant Care of the Universidade Federal Fluminense (UFF), Niterói, RJ, Brazil.

3. MSc, MD, Physician in the Radiology Department of the Clínica de Diagnóstico Por Imagem (CDPI), Rio de Janeiro, RJ, Brazil.

4. PhD, MD, Physician in the Radiology Department of the Clínica de Diagnóstico Por Imagem (CDPI), Rio de Janeiro, RJ, Brazil.

5. Tenured Adjunct Professor in the Department of Obstetrics of the Escola Paulista de Medicina da Universidade Federal de São Paulo (EPM-Unifesp), São Paulo, SP, Brazil.

Mailing address: Dr. Edward Araujo Júnior. Rua Belchior de Azevedo, 156, ap. 111, Torre Vitória, Vila Leopoldina. São Paulo, SP, Brazil, 05089-030. E-mail: araujojred@ terra.com.br.

Received August 3, 2016. Accepted after revision September 8, 2016. scarring, and diminished amniotic fluid volume, ultrasound has low sensitivity.

Magnetic resonance imaging (MRI) has been applied in situations in which ultrasound has low sensitivity, showing advantages in the evaluation of some malformations, such as cortical maturation disorders ${ }^{(8)}$. With respect to malformations in the fetal abdominal wall, MRI is typically used in the prognostic evaluation of intestinal atresia, gastroschisis, and omphalocele complications, permitting better perinatal management and parental counseling ${ }^{(9)}$. MRI is a more accurate method than is ultrasound for the characterization of the pelvic and abdominal extent of sacrococcygeal tumors $^{(10)}$, as well as providing more information on the compression of adjacent organs.

In this paper, we present MRI findings of the principal malformations of the fetal abdominal wall in the form of a pictorial essay.

\section{ABDOMINAL WALL DEFECTS AND TUMORS \\ Omphalocele}

Omphalocele is a defect of the anterior abdominal wall with encapsulation by the parietal peritoneum and herniation of the abdominal contents, resulting from failed migration of the lateral body ${ }^{(11)}$. Omphalocele occurs in $1 / 4000$ 
live births ${ }^{(12)}$ and is accompanied by other malformations in $72 \%$ of those births. It is also related to chromosome disorders, trisomies 18 and 13, which worsen the prognosis, being present in $30-40 \%$ of cases. The disorders most often accompanying omphalocele are those of a cardiac, genitourinary, gastrointestinal, or musculosketal nature, as well as defects of the neural tube, head, or neck ${ }^{(13)}$.

In prenatal screenings, omphalocele is successfully diagnosed with ultrasound in 66-93\% of cases. An MRI examination adds additional anatomic details in the evaluation of omphalocele. It shows the hernia sac, the central defect of the abdominal wall with herniated abdominal viscera surrounded by a thin capsule formed by the Wharton's jelly, which separates the abdominal contents from the amniotic fluid. The volume and its contents (liver, stomach, spleen, and colon) are variable. MRI demonstrates the central abdominal defect and herniated viscera, a thin capsule surrounding its contents and separating them from the amniotic fluid (Figure 1). The liver can be seen as a large, solid hypointense mass in T2-weighted sequences.
When omphalocele is accompanied by other malformations, the mortality rate is $80 \%$ and reaches $100 \%$ in individuals with a chromosome disorder. In cases of omphalocele without other malformations or chromosome disorders, perinatal mortality is only $19 \%$, revealing the importance of careful fetal morphologic evaluation for maternal counseling. The presence or absence of the liver in the hernia sac does not alter the prognosis ${ }^{(14)}$.

\section{Gastroschisis}

Gastroschisis is the herniation of the abdominal contents through a defect in the periumbilical abdominal wall on the right. It is a more rare anomaly than is omphalocele, with an incidence of $1 / 10,000$ to $6 / 10,000$ live births ${ }^{(15)}$. Unlike omphalocele, there is no hernia sac in gastroschisis and the abdominal contents are in direct contact with the amniotic fluid. Gastroschisis is accompanied by other malformations in $19-31 \%$ of cases, the most common being intestinal malformations such as atresia and stenosis. It presents complications similar to those of other intestinal anomalies, such as intestinal obstruction,

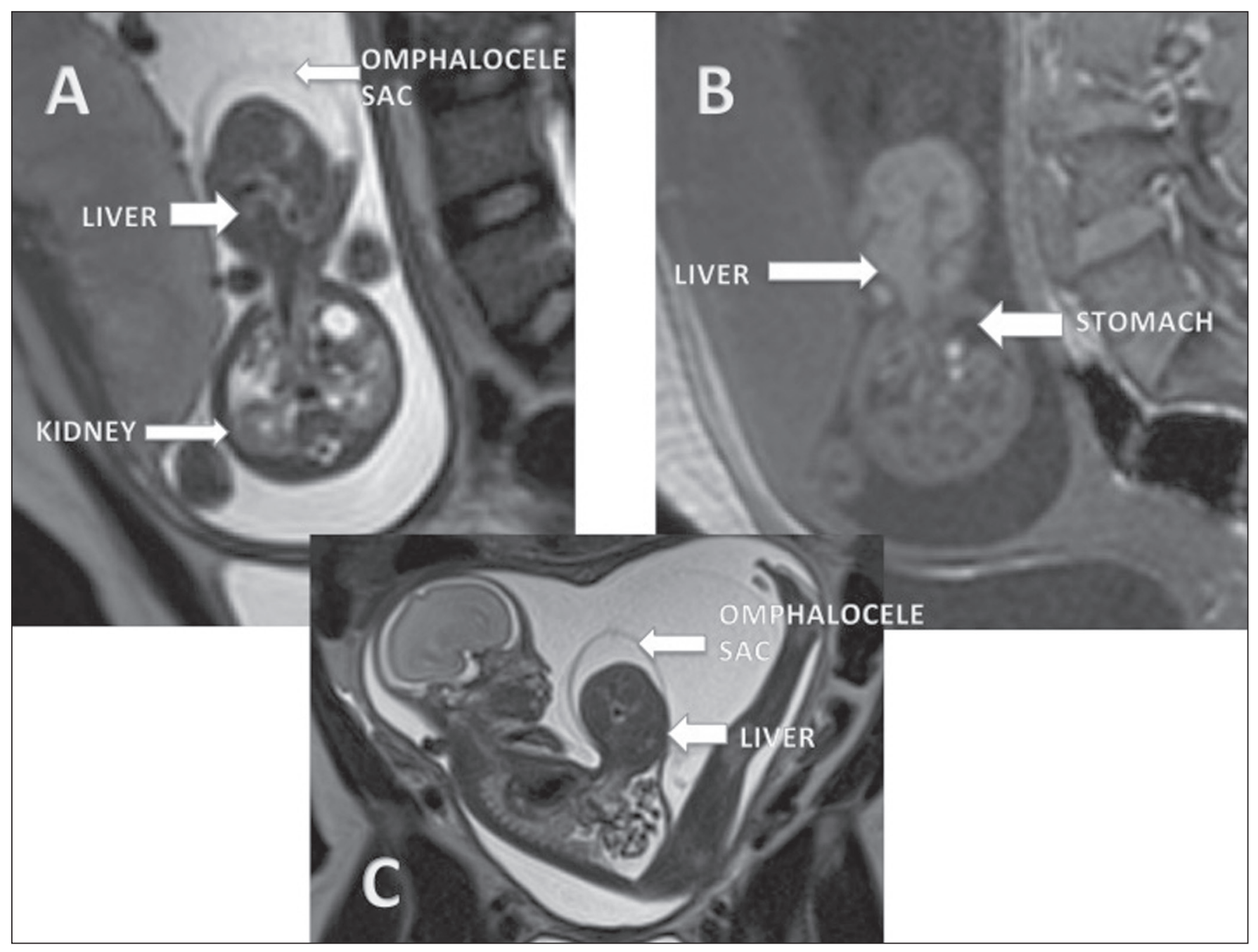

Figure 1. Omphalocele in a fetus at 22 weeks. A: Axial T2-weighted sequence showing a hernia sac with herniation of the liver. B: Axial T1-weighted sequence showing the hepatic herniation. C: Sagittal T2-weighted sequence showing an abdominal wall defect with a hernia sac containing the liver. 
perforation, peritonitis, necrotizing enterocolitis, short bowel syndrome, and fistulas.

Although the prevalence of gastroschisis has increased in recent years, the development of parenteral nutrition techniques has reduced mortality rates from $60 \%$ in the 1960 s to $3-10 \%$ in recent years, the principal prognostic factor being intestinal integrity ${ }^{(16)}$.

The correct evaluation of intestinal integrity is fundamental to the neonatal prognosis of gastroschisis. An MRI study shows intestinal loops herniated through the intestinal wall, floating freely in the amniotic fluid. The abdominal wall defect presents to the right of the umbilical cord insertion. Dilation and thickening of the loops could indicate abnormalities such as atresia and necrosis (Figure 2). The differential diagnoses are omphalocele rupture, herniation of the umbilical cord, and body stalk anomaly. The presence of solid structures floating freely indicates omphalocele rupture. The prognosis of gastroschisis is related to the bowel conditions at birth and to the presence of other malformations. Dilation larger than 17 $\mathrm{mm}$ and thickening of the loops of more than $3 \mathrm{~mm}$ can be related to high morbidity, as can polyhydramnios.

\section{Pentalogy of Cantrell}

First described in 1958, pentalogy of Cantrell is a combination of malformations in the abdominal wall, sternum, diaphragm, pericardium, and heart. It is a rare malformation, only a few hundred cases having been reported, and is more common in male fetuses. The malformations characteristic of the syndrome are midline, supraumbilical

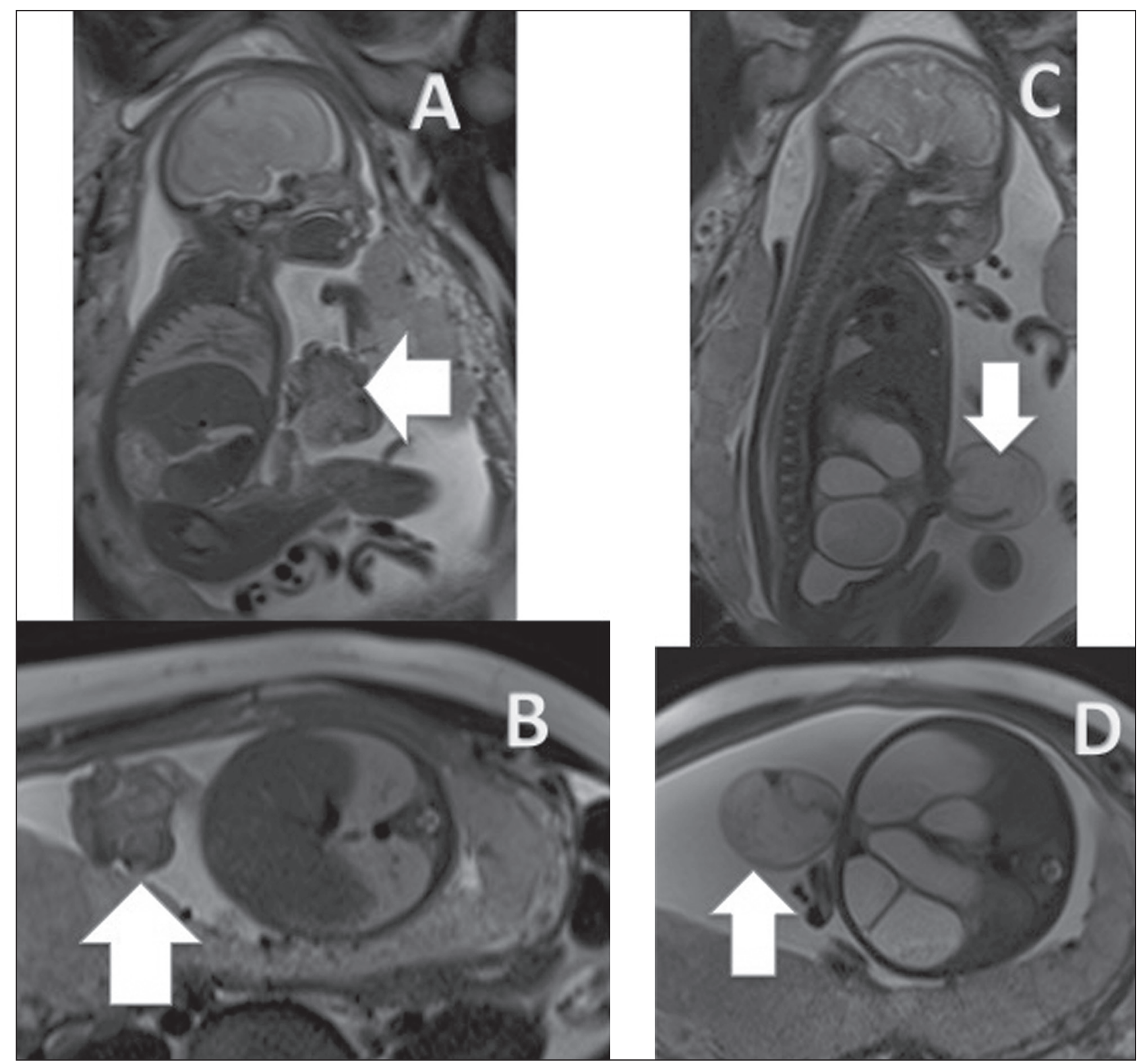

Figure 2. Gastroschisis. A,B: Sagittal T2-weighted sequence of a fetus at 27 weeks, showing an abdominal wall closure defect and intestinal herniation (arrows). C,D: Sagittal and axial T2-weighted sequences of the fetus at 33 weeks showing gastroschisis. Intestinal herniation with pronounced dilation of the intestinal loops, simulating a hernia sac (arrows). 
defects in the abdominal wall; defects in the caudal part of the sternum; malformation of the anterior diaphragm; and congenital heart disease.

In fetuses with pentalogy of Cantrell, the most common abdominal wall defect is omphalocele. A cleft in the lower part of the sternum, with herniation of the heart, characterizes malformation of the sternum. In $91 \%$ of cases, the defect is in the anterior diaphragm. Contiguity between the pericardial and peritoneal cavities is common. Among cardiac defects, significant and complex congenital heart diseases are the rule. The malformations most often accompanying pentalogy of Cantrell are those involving the thoracic and abdominal organs. Craniofacial and lower limb defects are also common (seen in $28 \%$ of cases). MRI shows omphalocele, ectopic heart, pleural effusion, and pericardial effusion. As shown in Figure 3, defects of the diaphragm can be difficult to assess by $\mathrm{MRI}^{(17)}$.

\section{Body stalk anomaly}

Body stalk anomaly consists of a variable group of malformations of the lower limbs and pelvic girdle, accompanied by defects in the abdomen and thorax ${ }^{(12)}$. With an incidence of 1/14,000 live births, its etiopathogenic factors include amniotic band syndrome and abrupt interruption of vascularization during embryonic development. The malformations most often described are abdominoschisis, which are typically left-sided and voluminous; defects in the thoracic wall; abnormal rotation of the lower limbs; congenital talipes equinovarus (clubfoot); brachydactyly; polydactyly; syndactyly; absence of lower limbs; and scoliosis (Figure 4). Body stalk anomaly is associated with facial and cranial defects such as exenphaly, encephalocele, and facial defects. Myelomeningocele, with hydrocephalus and Arnold-Chiari malformation, can also be present.
Among fetuses with body stalk anomaly, there is a high incidence of cardiac and diaphragmatic malformations. The umbilical cord is short or absent, the fetal thorax and abdomen adhering to the placenta, and there is herniated viscera. Amniotic band syndrome is seen in $40 \%$ of cases.

In cases of body stalk anomaly, MRI shows the placenta without evidence of an umbilical cord. Abdominal, thoracic, lower limb, craniofacial, and internal organ anomalies have a variety of presentations. At times, the herniated organs form a complex mass The amniotic band can be identified as a linear structure.

\section{SACROCOCCYGEAL TERATOMA}

Sacrococcygeal teratomas are tumors of embryonic origin resulting from the development and proliferation of pluripotent cells. The diagnosis is usually made in routine prenatal examinations. Neonatal mortality approximates $50 \%$ in cases of hydrops fetalis and prematurity.

MRI helps assess the extent of a sacrococcygeal teratoma, the involvement of adjacent organs, and the compressive effect of the lesion (Figure 5). During the prenatal period, MRI also evaluates the volumetric growth of the teratoma, which, together with the Doppler velocimetry study, classifies the disease as high or low risk. Because of the high morbidity and mortality associated with sacrococcygeal teratoma, surgery during gestation is a promising treatment $^{(18)}$.

\section{REFERENCES}

1. Castro AA, Morandini F, Calixto CP, et al. Ectopic ovary with torsion: uncommon diagnosis made by ultrasound. Radiol Bras. 2017;50:60-1.

2. Sala MAS, Ligabô ANSG, Arruda MCC, et al. Intestinal malrotation associated with duodenal obstruction secondary to Ladd's bands. Radiol Bras. 2016;49:271-2.

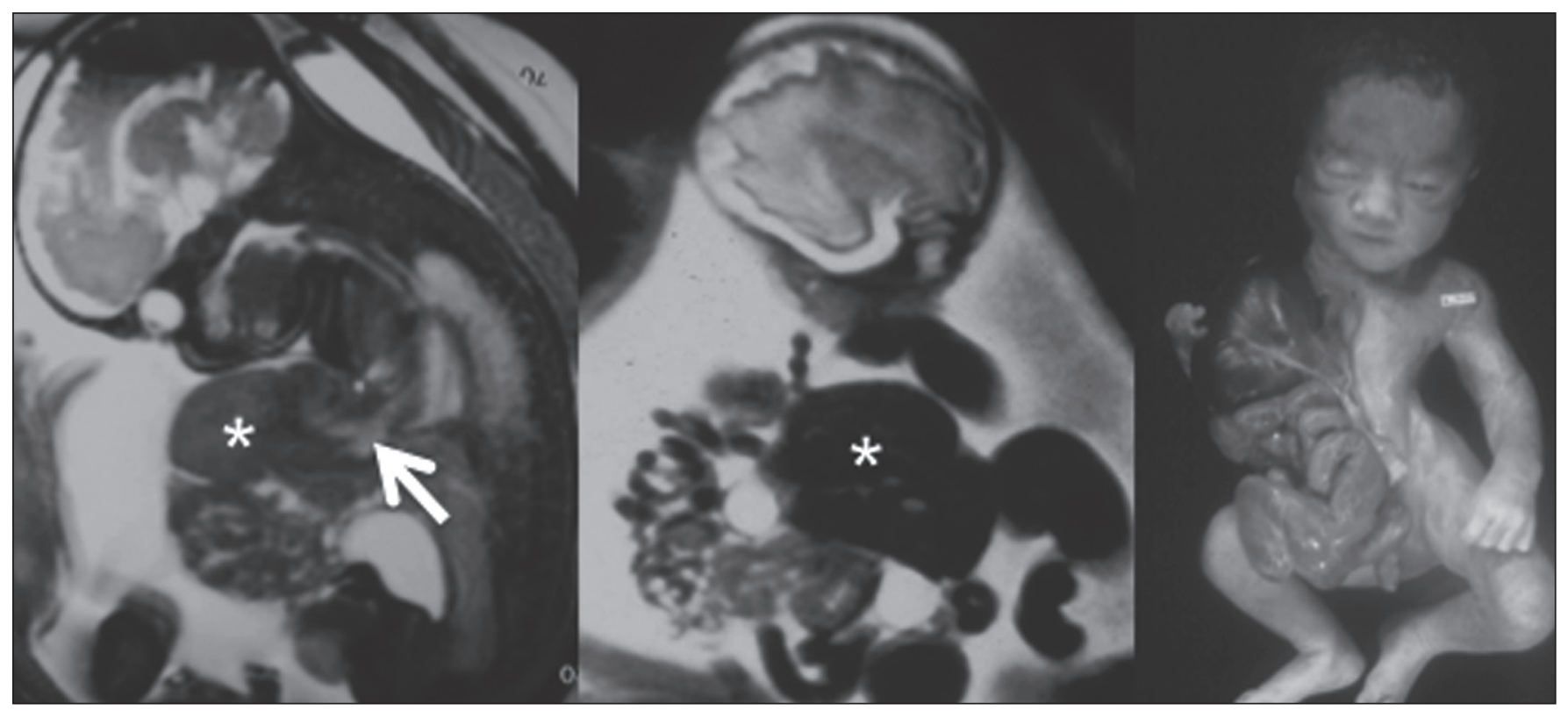

Figure 3. Pentalogy of Cantrell in a fetus at 27 weeks. Note protrusion of the liver (asterisk), heart (arrow), and intestinal loop through anterior defects in the thoracic and abdominal walls. 


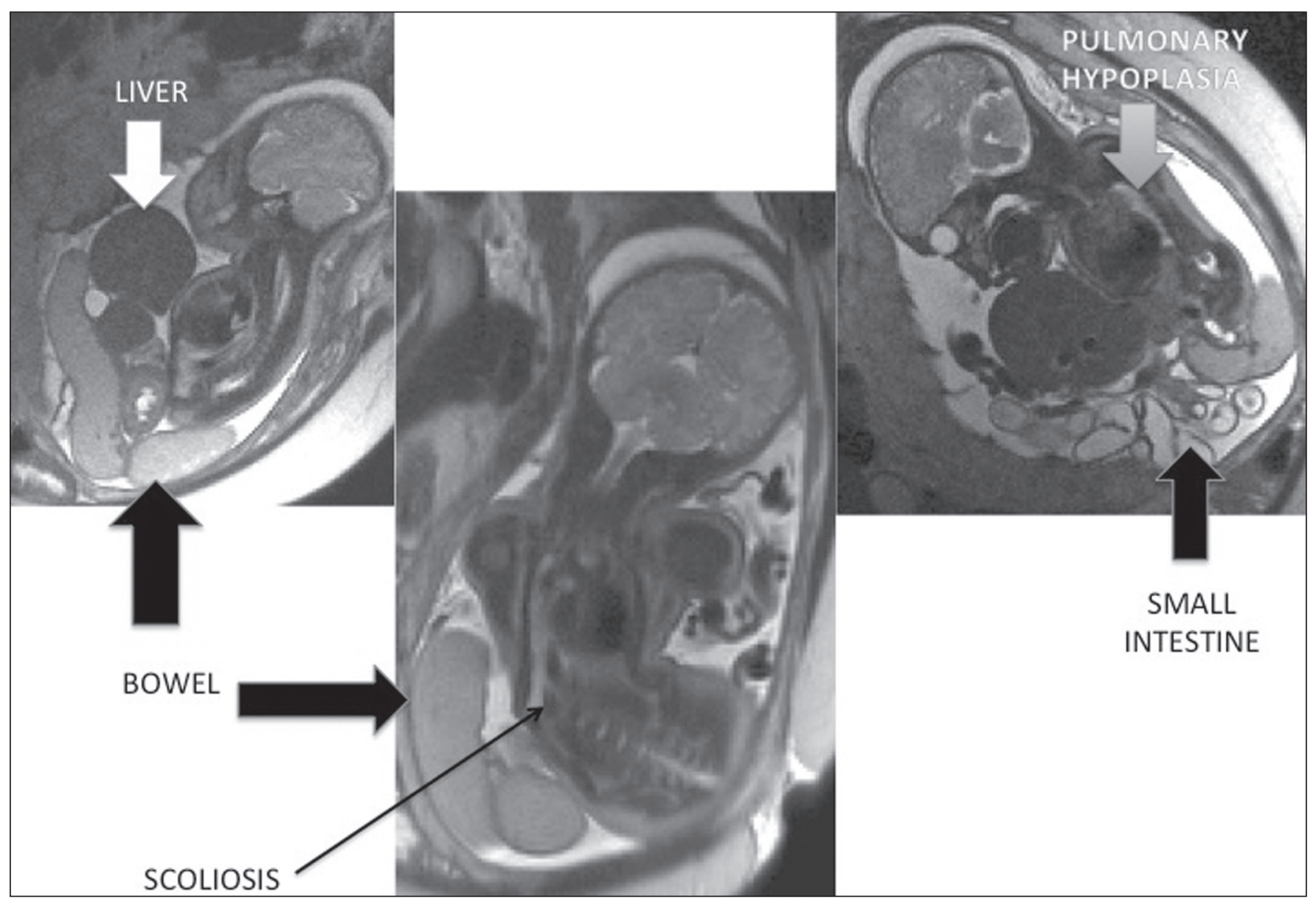

Figure 4. Body stalk anomaly. T2-weighted sequences showing herniation of the liver and intestine, with pulmonary hypoplasia and scoliosis.

Figure 5. Sacrococcygeal teratoma. A: Sagittal T2-weighted sequence showing a type III sacrococcygeal teratoma extending to the pelvis and abdomen in a fetus at 24 weeks (arrow). B: Sagittal T2-weighted sequence showing a type II sacrococcygeal teratoma in a fetus at 30 weeks (arrow).

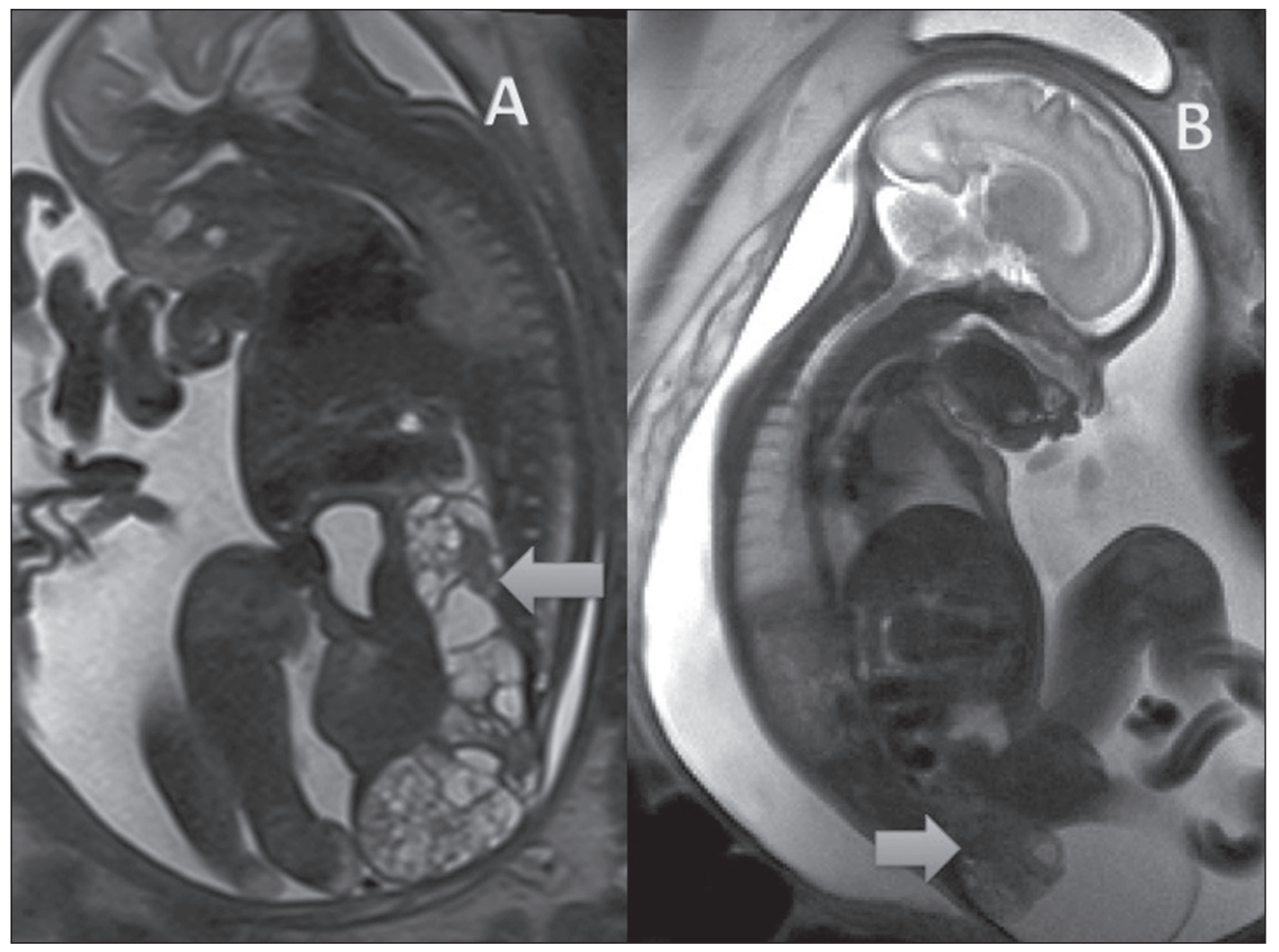


3. Niemeyer B, Muniz BC, Gasparetto EL, et al. Congenital Zika syndrome and neuroimaging findings: what do we know so far? Radiol Bras. 2017;50:314-22.

4. Werner Jr H, Santos JL, Belmonte S, et al. Applicability of threedimensional imaging techniques in fetal medicine. Radiol Bras. 2016;49:281-7.

5. Araujo Júnior E. Three-dimensional ultrasound in fetal medicine after 25 years in clinical practice: many advances and some questions. Radiol Bras. 2016;49(5):v-vi.

6. Werner H, Daltro P, Fazecas T, et al. Prenatal diagnosis of sirenomelia in the second trimester of pregnancy using two-dimensional ultrasound, three-dimensional ultrasound and magnetic resonance imaging. Radiol Bras. 2017;50:201-2.

7. Bertoni NC, Pereira DC, Araujo Júnior E, et al. Thrombocytopeniaabsent radius syndrome: prenatal diagnosis of a rare syndrome. Radiol Bras. 2016;49:128-9.

8. Rubod C, Robert Y, Tillouche N, et al. Role of fetal ultrasound and magnetic resonance imaging in the prenatal diagnosis of migration disorders. Prenat Diagn. 2005;25:1181-7.

9. Nakagawa M, Hara M, Shibamoto Y. MRI findings in fetuses with an abdominal wall defect: gastroschisis, omphalocele, and cloacal exstrophy. Jpn J Radiol. 2013;31:153-9.

10. Danzer E, Hubbard AM, Hedrick HL, et al. Diagnosis and characterization of fetal sacrococcygeal teratoma with prenatal MRI. AJR Am J Roentgenol. 2006;187:W350-6.
11. Emanuel PG, Garcia GI, Angtuaco TL. Prenatal detection of anterior abdominal wall defects with US. Radiographics. 1995;15:51730 .

12. Fogata ML, Collins HB 2nd, Wagner CW, et al. Prenatal diagnosis of complicated abdominal wall defects. Curr Probl Diagn Radiol. 1999;28:101-28.

13. Calzolari E, Bianchi F, Dolk H, et al. Omphalocele and gastroschisis in Europe: a survey of 3 million births 1980-1990. EUROCAT Working Group. Am J Med Genet. 1995;58:187-94.

14. Heider AL, Strauss RA, Kuller JA. Omphalocele: clinical outcomes in cases with normal kariotypes. Am J Obstet Gynecol. 2004;190: $135-41$.

15. Durfee SM, Downard CD, Benson CB, et al. Postnatal outcome of fetuses with the prenatal diagnosis of gastroschisis. J Ultrasound Med. 2002;21:269-74.

16. Bradnock TJ, Marven S, Owen A, et al. Gastroschisis: one year outcomes from national cohort study. BMJ. 2011;343:d6749.

17. Daltro P, Fricke BL, Kline-Fath BM, et al. Prenatal MRI of congenital abdominal and chest wall defects. AJR Am J Roentgenol. 2005;184:1010-6.

18. Coleman A, Kline-Fath B, Keswani S, et al. Prenatal solid tumor volume index: novel prenatal predictor of adverse outcome in sacrococcygeal teratoma. J Surg Res. 2013;184:330-6.

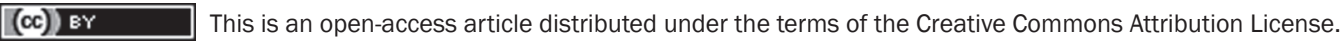

